APA: Agudelo Giraldo, O. A. (2020). ¿Es posible un sistema democrático de control de constitucionalidad en Colombia? En O. A. Agudelo Giraldo (Ed.), Derechos humanos, democracia y poder judicial (págs. 101-119). Editorial Universidad Católica de Colombia. https://doi.org/10.14718/9789585133020.2020.5

Chicago: Agudelo Giraldo, Oscar Alexis. “Es posible un sistema democrático de control de constitucionalidad en Colombia?" En Derechos humanos, democracia y poder judicial editado por Oscar Alexis Agudelo Giraldo, 101-119. Bogotá: Editorial Universidad Católica de Colombia. doi: $10.14718 / 9789585133020.2020 .5$

\title{
¿ES POSIBLE UN SISTEMA DEMOCRÁTICO DE CONTROL DE CONSTITUCIONALIDAD EN COLOMBIA?*
}

Oscar Alexis Agudelo Giraldo*

\section{Introducción}

En 1986, el Estado colombiano limitó, a través de la Ley 30, el porte y consumo de sustancias estupefacientes. Dicha regulación fue elevada a control de la Corte Constitucional, mediante acción de inconstitucionalidad interpuesta por la ciudadanía. En la Sentencia C - 221 de 1994, la Corte delimitó que:

1. De acuerdo a lo expresado por el artículo 51 de la Ley 30, al imponer la facultad, a favor del Estado, de dirigir a los consumidores de sustancias estupefacientes a centros de rehabilitación, se estaría incurriendo en la clásica prohibición del paternalismo jurídico y se estaría limitando el derecho al libre desarrollo de la personalidad.

2. Al criminalizar al consumidor con multas, e incluso con pena privativa de la libertad, se estaría contrariando el principio del daño. Entre tanto, no se

\footnotetext{
* El presente artículo es producto del proyecto Metodología y paradigmas de la investigación jurídica. Fase 2, del grupo de Estudios Legales y Sociales Phronesis, adscrito al Centro de Investigaciones Socio-jurídicas -CISJUC-, de la facultad de Derecho de la Universidad Católica de Colombia.

** Investigador del grupo de Estudios Legales y Sociales Phronesis, de la Universidad Católica de Colombia. Contacto: oaagudelo@ucatolica.edu.co. Bogotá D.C., Colombia.
} 
había demostrado que el consumidor de dosis mínima pudiera poner en peligro al sistema social.

La denominada peligrosidad del consumidor hizo parte de las unidades de análisis de la Sentencia C-221 de 1994. Esta provino de un juicio social en Colombia, derivado de una mal llamada moralidad convencional, en la que, de manera mayoritaria, los sectores sociales de tendencia conservadora consideraron que el consumidor era un potencial criminal, puesto que, bajo los efectos de sustancias estupefacientes, este carecía de control. En contraposición a ello, la minoría consumidora reclamó al Estado no ser tildada bajo el rótulo de criminal, puesto que la acción que ejercían no causaba daño a nadie. Siendo así, esto constituyó, para la Corte Constitucional, un problema democrático cuyo punto de partida fue un desacuerdo.

En el Derecho, los desacuerdos presentes en las sociedades políticas modernas resultan obvios; entre ellos está, por ejemplo, el relacionado con el concepto de justicia. En lo que concierne a la Sentencia C-221, el disenso, objeto de la misma, correspondió a una decisión atinente a los derechos básicos.

En la Filosofía Moral, este tipo de derechos suponen dos posiciones. La primera tiene que ver con la limitación para la adopción de políticas públicas que partan del cálculo costo-beneficio. La segunda concierne a las limitaciones a las decisiones mayoritarias, es decir, la delimitación del perímetro de lo que las mayorías no deben decidir (coto vedado).

Estas posiciones son el cociente de la tensión histórica latente entre el utilitarismo y los derechos de las minorías, la cual, en la actualidad, evoca la relación entre los derechos individuales y los derechos sociales, en materia de satisfacción por parte de políticas públicas (Rodríguez, 2007).

De ahí que el profesor Waldron (2005) preguntara: “Cómo debemos pensar los procedimientos democráticos y constitucionales, teniendo en cuenta que dichos procedimientos deben generar una política que se aplique también a aquellos que discrepan profundamente de si es correcta la teoría de la justicia elegida?" (p. 251).

Al persistir desacuerdos en las comunidades políticas, el Derecho debe obrar como mecanismo de solución a las discrepancias de la vida real, ya que este ostenta una pretensión de autoridad. Siendo así, su función "es construir 
esquemas comunes y orquestar la acción colectiva en circunstancias de desacuerdo" (Waldron, 2005, p. 252).

En materia del disenso, dos paradigmas han sido considerados como mecanismos de decisión colectiva: el constitucionalismo y la regla de las mayorías (Camarillo, 2011). En cuanto al primero, en sus bases obra la institucionalidad del control de constitucionalidad. Empero, la apuesta del profesor Waldron implica una ilegitimidad democrática sobre el control constitucional de las leyes, puesto que reivindica la tesis de la supremacía parlamentaria.

A partir de Unger, el profesor encontró una disociación entre Teoría del Derecho y democracia, vista en la limitación de los intereses mayoritarios por parte de los tribunales, los cuales no reflejan el derecho de un pueblo libre y democrático, marginalizando así la legislación y demostrando un desencanto por la justicia constitucional.

En defensa del derecho de la legislación, Waldron ha recordado que solo esta representa a la totalidad de los ciudadanos. Sin embargo, dado que la ciudadanía puede no estar en consonancia, propuso tres disconformidades posibles: “i) El desacuerdo sobre la afirmación de que algo sea derecho. ii) El desacuerdo sobre los derechos que tenemos. iii) El desacuerdo sobre el consenso acerca de cuáles son los derechos y libertades básicas" (Waldron, 2005, p. 270).

Ahora, recurriendo de nuevo al problema de los mecanismos de decisión colectiva, el autor sustentó que en respuesta a los desacuerdos opera la necesidad de la regla de la mayoría. Para él, este mecanismo no implica, en todos los casos, una tiranía. No obstante, el control de constitucionalidad también es útil para la determinación de decisiones colectivas. Aquí, la superación del disenso, por vía de decisión judicial, no limita el poder mayoritario, entre tanto el mismo tribunal depende del voto de la mayoría de sus miembros. De ahí que los mínimos del modelo constitucionalista sean: la primacía constitucional, que incluye el catálogo de derechos básicos, y la existencia de un control jurisdiccional de constitucionalidad de la legislación (Linares, 2015).

En este orden de ideas, para Waldron, el derecho de la legislación es el único mecanismo y procedimiento deliberativo que toma en serio el desacuerdo. Ello lo hace equiparable al derecho de tomar parte en la creación de las leyes, derivado como un derecho político a favor de la ciudadanía, el cual se traduce en el derecho al voto. 
Aquí se rescata la distinción entre los modelos rule of law y rule by law, la cual se basa en que la existencia de un control constitucional no democrático aparece como la continuidad del segundo de ellos. En otras palabras, el uso de las proposiciones of y by son fundamentales para discernir respecto a estos dos tipos. El modelo rule by law representa la idea de que el gobierno usa el derecho para controlar a la ciudadanía, mientras que el de rule of law representa un gobierno limitado por la ley (Waldron, 2008).

Las posiciones a favor del control judicial de constitucionalidad de las leyes suponen la existencia de una carta de derechos, la cual otorga poder a los tribunales para invalidar la legislación que transgreda los derechos básicos. Sin embargo, Waldron estableció que son las personas, cuyos derechos están en cuestión, las que deben decidir cuáles son estos, dándoseles así participación, en iguales términos, para dicha disposición. Como consecuencia de ello, se atribuye el principio de autoridad, no al control de constitucionalidad, sino a un mayoritarismo participativo, ya que "los desacuerdos sobre los derechos deberán ser resueltos por los sujetos de los desacuerdos" (Waldron, 2005, p. 254).

En síntesis, el límite de las decisiones mayoritarias no son los derechos básicos, sino lo que el órgano que ejerza el control de constitucionalidad establezca que es el contenido de los mismos. Por ello, siguiendo a Waldron, la respuesta a los desacuerdos, dada en la mayoría legislativa al representar a los electores, se convierte en materia de respeto y no injerencia por parte de los jueces (Verdugo, 2013). Estas consideraciones llevan a la siguiente pregunta: ¿Es posible un sistema democrático de control de constitucionalidad en Colombia?

Para responder a este problema, en el presente texto se sostienen tres hipótesis:

1. Adoptar un sistema democrático de control de constitucionalidad en Colombia requeriría una representación parlamentaria efectiva. Sin embargo, el ejercicio de la legislación en Colombia solo representa intereses económicos de grupos privados.

2. De acuerdo con la tesis de la representación argumentativa, no sería posible un control democrático de constitucionalidad en Colombia, puesto que no existe una racionalidad en el discurso democrático.

3. El sistema de control de constitucionalidad fuerte en Colombia, al ser un sistema contramayoritario, avala y justifica su existencia. 


\section{Las objeciones al control de constitucionalidad fuerte}

En la tradición continental europea, la construcción del paradigma del control de constitucionalidad debe su apogeo a la construcción simultánea de los Tribunales Constitucionales propuesta por Kelsen (2011). Para el autor, dicho control implicaba un examen acerca de la validez de las normas jurídicas, en el que podían confluir dos circunstancias que daban lugar a la inconstitucionalidad y, por lo tanto, a la expulsión de una norma del sistema jurídico.

Estas circunstancias eran, por un lado, la ausencia de validez formal, es decir, la constatación de que una norma jurídica no había sido elaborada conforme al procedimiento constitucional de creación; y, por el otro, la ausencia de validez sustancial, en otras palabras, la incompatibilidad entre el contenido de la norma jurídica elaborada y las disposiciones constitucionales vigentes (Alexy, 2015). Es importante aclarar que en la versión primigenia de una teoría de las normas, la apuesta de Kelsen corresponde a la suficiencia de la validez formal (Kelsen, 2011).

A su vez, y como nicho histórico, el origen del control de constitucionalidad se encuentra también en la propuesta de la Judicial Review, sustentada en el caso Marbury vs Madison (Amaya, 2010). Parte de su justificación obra en los desarrollos teóricos de Alexander Hamilton, quien en su defensa expuso que el hecho de que una Corte Suprema de Justicia tuviera la posibilidad de expulsar del ordenamiento jurídico una norma jurídica vigente o en proceso de elaboración, no implicaba la institucionalización de una superioridad de la rama judicial sobre la rama legislativa. En este caso, lo que se ratifica es la supremacía constitucional sobre las ramas del poder público, por vía de decisión judicial. La defensa de Hamilton corresponde, por tanto, a una no irrupción del principio de tridivisión del poder (Gargarella, 2012).

Por otro lado, recurriendo al argumento de Hamilton y reanudando la propuesta de Kelsen, en la construcción original de los Tribunales Constitucionales, el ejercicio del control de constitucionalidad es el mediador para una interpretación auténtica de la norma, posibilitando la superioridad de la rama judicial sobre las demás ramas del orden público. Dicha propuesta se configura en el debate Kelsen - Schmitt, cuya temática corresponde a la garantía del cumplimiento de la legalidad constitucional y a la preocupación sobre la continuidad existencial de 
la Constitución. En los albores del debate, fue precisamente Kelsen quien posicionó los Tribunales Constitucionales como defensores, y por tanto, intérpretes auténticos de las Constituciones Políticas. Por su parte, Schmitt dispuso en esta competencia que se encontraba a favor del presidente de la República (Schmitt, 2009).

De las dos posturas, la de Kelsen resulta ser la más conveniente. La existencia de regímenes jurídico-políticos, como el de la Alemania nazi, han demostrado que la promoción y protección de los derehos fundmamentales, insertos en las Constituciones Políticas, convienen en manos de jueces y no de políticos, entre tanto su protección corresponde a una cuestión de Derecho.

Siendo así, el control de constitucionalidad tiene su justificación en la crisis de los órganos políticos, en los cuales no persiste, de manera concomitante, una representación adecuada de la ciudadanía. Lo anterior, debido a que las decisiones políticas dependen del querer de determinados grupos de poder y a que el legislativo pocas veces toma en cuenta los reclamos reales hechos por los ciudadanos (Gargarella, 1997).

Ahora bien, en el norte del continente americano, frente a la idea de Judicial Review, aparecen críticas al modelo de control de constitucionalidad. Parafraseando a Gargarella, estas son: la crítica del argumento histórico, la crítica del argumento intemporal y la crítica del argumento de la interpretación.

La crítica del argumento histórico parte de desmentir que la Constitución encarna la voluntad del pueblo. Esto, en atención a que la Carta Política de los Estados Unidos es parcialmente legítima, pues algunos grupos poblaciones no fueron considerados como parte de su elaboración, por vía de teoría procedimental del discurso. Entre ellos estaban: los esclavos, las personas que no ostentaban una posición económica favorable, los afroamericanos, los indios nativos americanos y las mujeres (Gargarella, 1997).

Por su parte, la crítica del argumento intemporal estima que, si bien en la Constitución pasada se pudo llegar a un consenso (en términos de mayorías), esto no es razón suficiente para considerar que, en el futuro, algunas concepciones que hagan parte de ella no sean objeto de modificación. Dicho en otras palabras, la decisión política debe estar en manos de los ciudadanos actuales y no de los antepasados de estos (Gargarella, 1997). 
Finalmente, la crítica del argumento de la interpretación parte de reconocer que la hermenéutica del texto constitucional no se limita a su interpretación literal, por lo que requiere del empleo de herramientas explicativas divergentes (Gargarella, 1997).

Ahora, estas críticas sustentan problemas jurídicos, políticos y sociales para el sistema estadounidense. Algunos de estos han llegado a extenderse internacionalmente. Por ejemplo, desde la crítica del argumento histórico, se han originado tensiones democráticas entre aquellos ciudadanos estadounidenses que se autoproclaman y aquellos que son verdaderos nativos americanos. Estos desacuerdos radican en la fijación de políticas migratorias y de expulsión a los no ciudadanos.

Por otro lado, las críticas del argumento intemporal y del argumento de interpretación se pueden reducir a la búsqueda de herramientas hermenéuticas para la comprensión de los textos constitucionales. Por ejemplo, obrando en contra del argumento intemporal, subsisten como métodos de interpretación el denominado originalismo semántico y el de expectativa. Estos implican el entendimiento de la Constitución, a partir del sentido original dado en la referencia semántica que el edictor de la norma constitucional ha predeterminado, o de los efectos que se esperaban como resultado de la misma (Solum, 2008).

Sin embargo, la crítica del argumento intemporal colisiona con una de las fórmulas de solución al argumento de interpretación - dado en el método originalista-, puesto que esta, en materia de la denominada paradoja de la democracia, inclina la balanza a favor de las generaciones presentes, en detrimento de las pasadas.

A la postre, en virtud de la crítica del argumento de la interpretación, sobresalen métodos como el anticanon constitucional y la interpretación constructiva de los textos constitucionales, como formas de entendimiento auténtico (Green, 2011). En defensa de ellos, persiste la necesidad de dotar de contenido las normas constitucionales relativas a derechos fundamentales, adoptando una teoría de los límites externos, puesto que el argumento de las mismas aparece inicialmente como indeterminado (Agudelo, 2012).

De acuerdo a lo dicho, dotar de contenido los derechos fundamentales, insertos de manera taxativa e innominada en las Constituciones Políticas, resulta ser, en tiempo presente, una actividad dada en la jurisprudencia (teoría de los límites externos). No obstante, persiste como incógnita la cercanía entre jueces 
y ciudadanos, de tal manera que en el ejercicio de delimitar el contenido de las normas constitucionales medie una legitimidad democrática. La respuesta a dicho interrogante resulta ser negativa, ya que esta última solo se puede predicar de órganos elegidos democráticamente, en otras palabras, sobre los cuales el pueblo pueda ejercer control (Gargarella, 1997).

Bajo esta apreciación subyace, para la Teoría del Derecho Constitucional, la principal crítica u objeción a la figura del control de constitucionalidad fuerte. Esta tiene como fundamento la ausencia de legitimidad democrática, considerando que, generalmente, en dicho sistema los que tienen la última palabra son los jueces y estos no poseen ningún tipo de representación ni control electoral (Waldron, 2018).

Para sustentar esta objeción, deben ser caracterizadas la democracia y la legitimidad democrática. Waldron (2018) define la democracia como la unión de varios elementos, tales como la garantía de sufragio universal, la protección de derechos fundamentales, el establecimiento de elecciones periódicas y la existencia de mecanismos de elección representativa. En ese orden de ideas, la legitimidad implica

la capacidad de un sistema político y jurídico de generar respaldo para la implementación de las leyes y políticas, incluso por parte de aquellos que se opusieron a estas por razones sustanciales, es decir, por parte de aquellos que hicieron campaña en contra de esas políticas o leyes o que hubiesen votado en contra de ellas de haber tenido la oportunidad de hacerlo (Waldron, 2018, p. 16).

De la relación entre democracia y legitimidad subsiste la objeción al control de constitucionalidad. Los argumentos que sustentan esta posición tienen que ver con lo siguiente: primero, con que los jueces no son elegidos democráticamente; segundo, con que la elección de los magistrados de Los Tribunales Constitucionales no opera a través de mecanismos de elección representativa; tercero, con que esto conlleva que dichos operadores no representen democráticamente a la comunidad y que sobre estos no exista un control democrático vinculado a su actividad.

El problema concierne al control de constitucionalidad y a sus consecuencias, porque a través de la práctica jurisdiccional se nominan, reconocen o niegan derechos que son producto de dinámicas y exigencias del sistema social. Siendo así, 
nace otro interrogante: ¿La ausencia de legitimidad democrática del control de constitucionalidad implica revalorizar las consecuencias que este genera?

Dicha pregunta trae consigo el análisis de los efectos producidos por el ejercicio del control de constitucionalidad. Estos median en las figuras de los denominados legisladores positivos y negativos. La idea del juez constitucional como legislador negativo implica la posibilidad, por vía de competencia (generada en la indeterminación de la Carta Constitucional), de expulsar una norma jurídica del sistema, en la medida en que sea efectivo el grado de incompatibilidad; esto se denomina como el control de constitucionalidad fuerte (Trovao, 2015).

Su antónimo, el control de constitucionalidad débil, se caracteriza porque a pesar de que el órgano declare la inconstitucionalidad de una norma, esta no es expulsada del ordenamiento jurídico, sino que tal decisión es tomada en cuenta por el parlamento, de tal modo que este se debe hacer cargo de modificar la norma para hacerla compatible con el ordenamiento (Melero, 2018). Ejemplos de este tipo de control de constitucionalidad se encuentran en países como Canadá, donde existe la denominada notwithstanding clause o cláusula derogatoria, en la que se establece la posibilidad de legislar sin control o escrutinio judicial. De igual manera, en Nueva Zelanda, las cortes no tienen la posibilidad de expulsar normas de su ordenamiento jurídico ni tampoco se pueden negar a aplicarlas, así vayan en contravía de los derechos humanos; es decir, no predeterminan el ejercicio de la inconstitucionalidad por excepción (Waldron, 2018).

La existencia de un control de constitucionalidad débil cobra fuerza, debido a que el argumento sobre el cual se soporta está relacionado con la ausencia de elección democrática de los jueces, quienes, a su vez, tampoco tienen responsabilidad política. De esta manera, se infiere que la tarea de expulsar normas del sistema jurídico corresponde originalmente al legislativo, en vista de que su elección es democrática y está sometida al control de las elecciones periódicas (Waldron, 2018).

De esta forma, Waldron (2018) posiciona la figura del control de constitucionalidad débil como el punto medio que soluciona la tensión entre el poder legislativo y el poder judicial. Esta se produce en la medida en que, atendiendo al principio de racionalidad de la legislación, el edictor de las normas jurídicas propone mecanismos y planes de acción para cumplir con los propósitos de las mismas. Sin embargo, los medios dados para alcanzar dichos propósitos pueden resultar 
inefectivos, ineficientes, desproporcionados e inconstitucionales, lo que genera la tacha del proyecto de ley, por vía del ejercicio del control de constitucionalidad.

A su vez, las prácticas constitucionales han demostrado el fin del principio de tridivisión del poder. Los Tribunales Constitucionales, al interpretar problemas jurídicos, conjugados con varias normas constitucionales, nominan y crean, por vía de jurisprudencia, nuevos derechos fundamentales (Bulygin, 2003).

Las anteriores situaciones demuestran que la tensión entre el poder legislativo y el judicial es producto del ejercicio del control de constitucionalidad fuerte. Por esta razón, Waldron sustenta que el mecanismo de solución para ello es el posicionamiento, en los sistemas jurídicos, del control débil. Sin embargo, esto requiere un máximo nivel de efectividad del principio de racionalidad de la legislación, entre tanto, para una racionalidad jurisdiccional se necesita de una racionalidad legislativa previa (Atienza, 1991).

Por otro lado, del poder judicial frente al ejercicio del control de constitucionalidad se ha predicado un carácter contramayoritario, que propende por la defensa, por vía de decisión judicial, de los derechos de las minorías o, en otras palabras, el impedimento de la imposición del derecho de la histeria colectiva de las mayorías sobre las minorías. Esto conlleva que el respeto a los jueces resida en el hecho de que estos deben proteger los derechos fundamentales contra las mayorías populistas o enardecidas (Friedman, 2005).

Sin embargo, para Waldron las Cortes no son realmente contramayoritarias, pues, en el ejercicio de deliberación, emplean el método mayoritario (mayoría simple - mitad más uno de los magistrados), lo que a su juicio constituye una violación a los derechos políticos de las mayorías (Waldron, 2018).

Al respecto, se elucidan los siguientes tres errores en el modelo de Waldron:

1. Persiste una confusión entre contenido y forma, en lo que se refiere a la decisión judicial, en materia de control de constitucionalidad. Esta puede hacerse evidente recurriendo al uso de la denominada falacia naturalista. La forma de las decisiones judiciales, producto del ejercicio del control de constitucionalidad, debe darse de acuerdo a una mayoría simple (juicio de deber), lo cual no quiere decir, por vía de inferencia lógica, que el contenido de la decisión judicial sea mayoritario (juicio de ser) (Navarro, 2007). El error de Waldron es inferir que la manera de deliberar conlleva necesariamente el contenido de la decisión. En otras palabras, este 
podría ser mayoritario o contramayoritario. Casos como el de la Corte Constitucional de Colombia, ejemplifican el carácter contramayoritario del contenido de las decisiones judiciales.

2. Resulta plausible el argumento de Dworkin, frente al de Waldron, respecto al carácter contramayoritario del poder judicial. Precisamente, Dworkin, al distinguir entre argumentos políticos y de principio, al mismo tiempo diferencia las decisiones judiciales contramayoritarias de las mayoritarias (Gaviria, 2014). Su apuesta, en contraposición al paradigma utilitarista, es la defensa de los derechos individuales o derechos de las minorías, a través de las decisiones judiciales (Dworkin, 2002).

3. La forma de deliberación, en el ejercicio de los tribunales constitucionales, está marcada por una mayoría simple, cuestión que no demerita la idea de que los distintos puntos de vista del sistema social puedan estar representados en la misma. Al respecto, ha de recordarse que la deliberación de un problema jurídico, originado a través del ejercicio del control de constitucionalidad, se desarrolla metodológicamente a través de la formulación de razonamientos dialécticos, los cuales implican una lógica de los juicios de valor, que corresponden a los juicios socialmente relevantes. Incluso, herramientas metodológicas como la nueva retórica y la tópica jurídica sugieren, para los ámbitos de la decisión judicial, invocar aquellos argumentos que tengan la posibilidad de convencer a un auditorio universal (Viehweg, 1964).

\section{Alternativas: mayoría calificada, control constitucional popular y jurados constitucionales}

Una vez suscitado, en términos de Waldron, el carácter no democrático del control de constitucionalidad, sobreviene una nueva incógnita: ¿Su ausencia de legitimidad democrática es elemento suficiente para demeritarlo? Al respecto, se han nominado vías alternas. Sin embargo, en el presente texto se sustenta la necesidad de un control de constitucionalidad fuerte para América Latina, haciendo hincapié en Colombia.

Para no desaparecer radicalmente la figura del control de constitucionalidad fuerte, Waldron examina la posibilidad de optar por un sistema que exija 
mayorías calificadas y no mayorías simples (Waldron, 2018). Como ejemplo de ello, propone los casos de Nebraska y Dakota del Norte en Estados Unidos, en los que se requieren, para expulsar una norma jurídica, cuatro votos de cinco, o cinco de siete, respectivamente, sustentando la unanimidad en la votación. Este argumento podría resultar contraproducente, en atención a que la mayoría simple refleja la pluralidad interpretativa entre aquellos que deben decidir.

Como alternativa a la idea de mayoría calificada, y con la pretensión de hacer partícipe al pueblo en el ejercicio del control de constitucionalidad, aparece la figura de los jurados constitucionales. Estos no cuentan con el monopolio del control de constitucionalidad, sino que actúan de manera paralela al Tribunal Constitucional. Esto implica que la competencia de expulsar normas del sistema, a través del control judicial, es delegada a los jurados constitucionales. Frente a la pregunta del orden cuantitativo, Spector considera, recurriendo al modelo ateniense, que el jurado debe estar conformado por quinientas personas, cuya finalidad es garantizar la diversidad de puntos de vista (Spector, 2015).

Aparece entonces una tercera alternativa, denominada por Barry Friedman como control constitucional popular mediado, la cual hace posible la superación de la tensión existente entre el control judicial y la democracia. Lo anterior, en la medida en que las encuestas de opinión pública demuestran que las decisiones judiciales, en la gran mayoría de casos, cuentan con apoyo popular; así mismo, en que al existir una discrepancia entre la decisión judicial y la opinión popular se dan dos posibilidades, que la gente cambie de opinión o que los jueces lo hagan situación que sucede generalmente-; finalmente, en que al darse una discrepancia entre la decisión judicial y el sentir popular, la mayoría de las personas apoyen la decisión judicial (Friedman, 2005).

Cabe anotar que el control constitucional popular actúa sobre los jueces de una manera ex post, es decir, una vez surtida la decisión judicial, esta se somete a un juicio de adhesión popular. En cambio, la crítica a la falta de legitimidad democrática se presenta como una condición ex ante a la deliberación por parte de los tribunales constitucionales. Al respecto, cuando las decisiones judiciales no cuentan con una única respuesta y persiste una amalgama de posibilidades de solución, la incógnita del operador jurídico es por cuál de ellas proceder.

Perelman propone que el elemento de decisión judicial se debe configurar con ayuda de la fórmula "lo que es justo aquí y ahora" (Perelman, 1997). Esta 
implica un juicio de adhesión social frente al contenido de la decisión judicial. Sin embargo, el acercamiento de los jueces al sistema social no es personalizado, puesto que ellos no hacen trabajo de campo ni aplican instrumentos cualitativos o cuantitativos para preguntar a las personas cuál podría ser la solución justa frente a determinado caso. Por lo tanto, una forma de hacer operativa esta fórmula es el control ex post, donde, una vez surtida la decisión judicial, es posible, a través de instrumentos de medición, conocer la cohesión social, y por tanto popular, de la decisión judicial que se toma en el ejercicio del control de constitucionalidad.

En este sentido, con el modelo del control de constitucionalidad popular, la idea de supremacía judicial, típica del modelo fuerte, resulta una expresión exagerada. Cuando la Corte toma una decisión judicial sobre la cual no existe adhesión popular, le es dado al sistema social ejercer mecanismos de presión, tales como la movilización social o la protesta pacífica (Friedman, 2005).

\section{En defensa del control de constitucionalidad fuerte: la idea de representación argumentativa}

En las acotaciones de Waldron se infiere una posición radical, derivada de la ausencia de legitimidad democrática en el control de constitucionalidad fuerte. Esta posición puede resultar incluso falaz, en la medida en que se basa en un todo o nada, puesto que al debatir quién debe tomar la última decisión política fundamental, el autor no tiene en cuenta la posibilidad de un trabajo mancomunado entre el legislativo y el judicial, impidiendo la posibilidad de un sistema de pesos y contrapesos. En este orden de ideas, si el parlamentario tiene la última palabra, la pregunta subsiguiente es ¿quién lo controla? (Verdugo, 2013).

Derivadas de la idea de pesos y contrapesos confluyen las nociones del aspecto positivo y negativo del control de constitucionalidad. La distinción entre ambas corresponde al ejercicio de poner en una balanza las decisiones judiciales relativas a la colisión de derechos fundamentales con bienes colectivos. El ejercicio de la legislación, en correspondencia con sus bases utilitaristas, usualmente parte de satisfacer el alcance de estos últimos. Así, el aspecto negativo del control de constitucionalidad implica la interferencia del poder judicial sobre el poder legislativo. En la medida en que esta sea menor, se considera que el grado de legitimidad puede ser mayor. Por otro lado, el aspecto positivo implica inclinar 
la balanza a favor de la democracia y de la satisfacción de los bienes colectivos (Alexy, 2015).

Para esto, Alexy justifica el control de constitucionalidad fuerte a partir de la teoría de los principios y de la teoría de la representación argumentativa. En la medida en que los derechos fundamentales adquieren categoría de principio $\mathrm{y}$, por lo tanto, de mandatos de optimización, su forma de satisfacción puede ser gradual, al contrario de lo que ocurre en el modelo de reglas. Cuando una norma jurídica, elaborada por el legislador y que supone la representación democrática del pueblo, satisface derechos, intereses y metas colectivas, pero al mismo tiempo transgrede derechos fundamentales, resulta necesario que en el ejercicio del control de constitucionalidad la decisión sea contramayoritaria. Lo anterior, encontrando en la ponderación un mecanismo útil para justificar dicho carácter del control fuerte. De tal manera, para Alexy, el control de constitucionalidad opera como aquella figura que denota una superioridad de los derechos fundamentales frente a la legislación parlamentaria, puesto que su fundamento lógico es el principio de contradicción (Alexy, 2006).

En este sentido, Alexy justifica la existencia del control de constitucionalidad fuerte, delimitando la necesidad, a partir de casos concretos, del argumento negativo, siempre que el legislador transgreda los límites ponderativos. Ello no equivale a la superposición del argumento negativo sobre el positivo, sino al entendimiento de que estos pueden ser emparejados a partir de las nociones clásicas de constitucionalismo democrático.

El argumento positivo, visto desde el control de constitucionalidad, cuenta con dos variantes. La primera, protege las condiciones reconocidas en una democracia, lo que acarrea la legitimidad del control, ya que, en la actualidad, el derecho a disentir también es objeto de protección (Alexy, 2015). La segunda, deriva en la denominada representación argumentativa, que se puede sustentar en cuatro premisas:

1. El control de constitucionalidad conlleva un ejercicio de la autoridad del Estado.

2. Todo poder es legítimo si tiene fundamento en el pueblo.

3. Por lo tanto, el control de constitucionalidad es legítimo si y solo si reside en el pueblo.

4. Si reside en el pueblo, entonces debe representarlo (Alexy, 2015). 
De acuerdo a las cuatro premisas, el control de constitucionalidad es legítimo en tanto es compatible con la democracia. Esto solo es posible cuando media una representación argumentativa. Para ello, Alexy determina dos condiciones: la primera, es la existencia de argumentos correctos y razonables en la justificación de la decisión judicial; la segunda, es la existencia de personas razonables, dispuestas a aceptar argumentos racionales (Alexy, 2015).

¿Qué hace que el argumento sea correcto, desde el punto de vista de su justificación? Y, ¿es posible el modelo de Waldron en democracias donde las personas aceptan y formulan argumentos no racionales?

Para responder las preguntas anteriores, se hacen indispensables tanto la teoría del discurso práctico racional como la idea de democracia sustancial. En cuanto a la primera, viéndose la argumentación jurídica desde el punto motivacional de la decisión judicial -una forma del discurso práctico racional-, un argumento es correcto y razonable en la medida en que corresponda al Derecho. Es decir, siempre que no transgreda las reglas del discurso jurídico, en las que los derechos fundamentales aparecen como límite en la actividad argumentativa para el poder legislativo y judicial.

Todo argumento de una decisión judicial es correcto, en tanto se dirija a las personas conforme a las reglas mismas del discurso jurídico, suponiendo que los individuos, al ser tratados de forma racional, lo van a aceptar racionalmente. De ahí que, en el ejercicio del control de constitucionalidad, cuando la Corte emplea argumentos destinados a convencer a un auditorio universal, por referirse a este como seres racionales, la decisión se convierte en democrática.

No hay que olvidar que coexisten intereses democráticos que, a pesar de ser legítimos, constituyen ideas irracionales. En este sentido, la noción de constitucionalismo democrático impone límites a la actividad discursiva y procedimental, validando que no todo argumento legítimo y democrático es conforme a derecho (Ferrajoli, 2004).

La anterior posición supone, en respuesta a la segunda pregunta, que el control de constitucionalidad solo es democrático en la medida en que se dirige a seres racionales. En otras palabras, si este recae sobre intereses democráticos irracionales, la Corte Constitucional tiene como función morigerar las reglas del discurso y no atenderlos. En este orden de ideas, el error en la figura de Waldron opera en la idealización de sociedades democráticas racionales. Siendo así, ¿un 
interés democrático originado en un prejuicio, constituye un interés democrático racional?

La respuesta es demeritoria. Al respecto, la aparición de intereses democráticos, o incluso mayoritarios, es una cuestión típica del convencionalismo. Sin embargo, su límite se zanja en qué sujetos racionales convergen en intereses comunes y morales. Precisamente, Dworkin sienta un baremo para determinar cuándo la moralidad convencional es o no racional, a través de cuatro filtros:

1. No es convencional una moral basada en prejuicios.

2. Si el sistema de creencias de una persona arroja repulsión hacia un grupo de personas y, se evidencia que dicha repulsión es una reacción emocional.

3. Fundamentar la posición moral en una posición de hecho falsa.

4. Basar mi posición moral en creencias ajenas (Dworkin, 1985, p. 335).

Al respecto, la experiencia democrática y constitucional del sistema jurídico colombiano demuestra la inexistencia de personas razonables, dispuestas a aceptar argumentos racionales (segunda característica de la representación argumentativa). Sírvase como caso ejemplificante el desacuerdo frente a la posibilidad de instaurar medidas a favor de los menores, como la cadena perpetua para violadores.

Durante los años 2008, 2009 y 2010, la Senadora Gilma Jiménez impulsó la convocatoria a un referendo, a través del cual se pretendía modificar el artículo 34 de la Constitución Política, que en su formulación lingüística prohíbe las penas de destierro, prisión perpetua y confiscación. Desde su ámbito de aplicación, los destinatarios de esta posible reforma eran los sujetos declarados culpables de haber cometido el delito de violación en contra de menores de edad.

La propuesta tuvo un amplio espectro de legitimidad democrática. Sin embargo, los fundamentos eran irracionales, ya que correspondían a una propuesta subyacente a juicios emocionales, lo cual contrariaba las reglas del discurso jurídico y constituía, a su vez, una falacia ad misericordiam. Adicionalmente, la propuesta era direccionada por una congresista, lo que implicaba el ejercicio del derecho de la legislación. Sin embargo, la Corte Constitucional de Colombia, a través de la Sentencia C-397 de 2010, demeritó la propuesta y la declaró inconstitucional. El caso sirvió para demostrar que existen intereses democráticos irracionales, que 
irrumpen con la idea de representación argumentativa, lo cual evidencia la necesidad de la existencia de un control de constitucionalidad fuerte.

\section{Conclusiones}

Instaurar un modelo democrático de constitucionalidad para países como Colombia, requiere una representación parlamentaria efectiva. Sin embargo, el Congreso de la República resulta ser una de las instituciones con peor imagen de favorabilidad en el país, respecto a la ciudadanía. La razón está en la ponderación de intereses económicos privados y la representación ciudadana, cuyos resultados han demostrado múltiples casos de incumplimiento en la racionalidad de la legislación colombiana.

A su vez, ante la inexistencia de una representación argumentativa, vista en los intereses democráticos irracionales del elector, cobra raigambre el control judicial de constitucionalidad. Por otra parte, en el modelo de Waldron se encuentra una propuesta ideal, que no corresponde a la realidad y a las contingencias democráticas de Latinoamérica.

Por último, las sentencias producto del control judicial que hace la Corte Constitucional en Colombia, cuyo carácter es contramayoritario y progresista, demuestran su legitimidad desde tres puntos de vista:

1. Representan democráticamente los intereses de los grupos menos favorecidos por ocasión de la regla de la mayoría.

2. Su legitimidad no puede ser desligada de la legalidad, vista en términos de normas de competencia.

3. Desde el punto de vista del argumento intemporal, nominan y dan garantía a los derechos que perfilan las sociedades democráticas modernas, en virtud de la dinámica social. 


\section{Referencias}

Agudelo, O. (2012). Restricción, limitabilidad y derechos fundamentales: aportes para una teoría sistemática de los derechos fundamentales como derechos limitables. En E. Castro, Crítica y fundamentación de la política y de los derechos humanos (pp. 143-167). Bogotá: Universidad Libre de Colombia.

Alexy, R. (2006). Ponderación, control de constitucionalidad y representación. En P.A. Ibáñez, Jueces y ponderación argumentativa (pp. 1-18). México: Universidad Nacional Autónoma de México.

Alexy, R. (2015). Control judicial de constitucionalidad como representación argumentativa. En J.G. Fabra, Filosofia del derecho constitucional. Cuestiones fundamentales (pp. 219234). México: Universidad Nacionl Autónoma de México.

Amaya, J. (2010). Marbury Vs Madison. O de antiguas y modernas tensiones entre democracia y constitución. Revista de Estudios Jurídicos, 1-22.

Atienza, M. (1991). Razón práctica y legislación. Revista mexicana de estudios parlamentarios, 1(3), 9-31.

Bulygin, E. (2003). Los jueces ¿crean derecho? Isosnomía, (18), 6-25.

Camarillo, J. (2011). Regla de la mayoría y democracia constitucional. Heurística jurídica, (3), 43-62.

Dworkin, R. (1985). A matter of principle. Cambridge: Harvard University Press.

Dworkin, R. (2002). Los derechos en serio. Barcelona: Ariel.

Ferrajoli, L. (2004). Derechos y garantías. La ley del más débil. Madrid: Trotta.

Friedman, B. (2005). Las posibilidades normativas del control judicial de constitucionalidad: una respuesta a Roberto Gargarella. Revista Jurídica de la Universidad de Palermo, 169-173.

Gargarella, R. (1997). La dificultad de defender el control judicial de las leyes. Isonomía, (6), 55-70.

Gargarella, R. (2012). La justicia frente al gobierno. Sobre el carácter contramayoritario del poder judicial. Quito: Centro de estudios y difusión del derecho constitucional.

Gaviria, J. (2014). Democracia y control de constitucionalidad en el pensamiento de Ronald Dworkin. Eunomia. Revista en cultura de la legalidad, 361-368.

Green, J. (2011). The Anticanon. Harvard law review, 125(2), 380 - 474.

Kelsen, H. (2011). La garantía jurisdiccional de la constitución (la justicia constitucional). Anuario Iberoamericano de Justicia Constitucional, 249-300. 
Linares, S. (2015). El control de constitucionalidad: la democracia deliberativa epistémica y la dificultad contramayoritaria. En J.S. Fabra, Enciclopedia de Filosofia y teoría del derecho, Vol. 3 (pp. 1959-1990). México: Universidad Nacional Autónoma de México.

Melero, M. (2018). Constitucionalismo débil. Eunomia. Revista en cultura de la legalidad, 198-210.

Navarro, P. (2007). Normas condicionales y falacia naturalista. Doxa. Cuadernos de Filosofía del derecho, 601-616.

Perelman, C. (1997). El imperio retórico. Bogotá: Norma.

Rodríguez, C.U. (2007). Los derechos sociales en serio: hacia un diálogo entre derechos y politicas públicas. Bogotá: Centro de estudios de derecho, justicia y sociedad.

Schmitt, C. K. (2009). La polémica Schmitt / Kelsen sobre la justicia constitucional: el defensor de la constitución versus ¿quién debe ser el defensor de la constitución? Madrid: Tecnos.

Solum, L. (2008). Semantic originalism. Illinois public law and legal theory Research papers series, 1-172.

Spector, H. (2015). Un sistema democrático de control de constitucionalidad. En J.G. Fabra, Filosofia del derecho constitucional. Cuestiones fundamentales (pp. 278-293). México: Universidad Nacional Autónoma de México.

Trovao, P. (2015). Tribunal constitucional - ¿Un legislador negativo o positivo? Revista de Derecho UNED, (16), 713-740.

Verdugo, S. (2013). La discusión democrática sobre la revisión judicial de las leyes de diseño institucional y modelos constitucionales. Revista Chilena de Derecho, 40(1), 181-223.

Viehweg, T. (1964). Tópica y jurisprudencia. Madrid: Taurus.

Waldron, J. (2005). Derecho y desacuerdos. Madrid: Marcial Pons.

Waldron, J. (2008). The concept and the rule of law. Georgia law review, 1-61.

Waldron, J. (2018). Control de constitucionalidad y legitimidad política. Dikaion, 7-28. 
